\title{
SUCCESSFUL ROAD SAFETY INITIATIVES IN DUBAI
}

doi:10.1136/injuryprev-2012-040580a.2

M Bin Adai, H Al Banna*. Roads and Transport Authority, P.O. Box 118899 Dubai, UAE

Background Dubai is one of the fastest growing cities in the world and aims to provide world class services in all sectors. The economy boom, the large increase in population and the ease of car ownership has had a direct effect on the number of traffic accidents.

Objectives The Roads and Transport Authority was born in 2006 with the vision of 'safe and smooth transport for all' is responsible for designing, constructing, maintenance of road infrastructure, safety improvement programmes. We would like to take this 
opportunity to shed light on the on-going and future road safety initiatives and schemes that helped to reduce road fatalities on Dubai roads.

Methods The introduction of various traffic safety improvement projects and schemes such as a Road Safety Strategy, Pedestrian Safety and Mobility Action Plan, Road Safety Auditing, Accident Blackspots programmes, Road side improvement programmes, Work Zone improvement programmes, Speed Management programmes, Traffic Awareness Programmes, Zone wise auditing programmes, Traffic calming measures in residential and school zones and also adopting new standards and manuals which are based on best international practices.

Results The above systematic approach, successful road safety programmes and initiatives have contributed to reducing the rate of fatalities in Dubai from 21.9 fatality/100 k population in 2006-6.7 fatality/100 k population in 2011.

Significance The continuous and systematic initiatives above are certainly leading the way in the field of Traffic Safety and have managed to exceed all expectations in Dubai, the region and the world as far as traffic safety improvements are concerned. 